\title{
Improving Student Readiness for Inquiry-Based Learning: An Engineering Case Study
}

\author{
https://doi.org/10.3991/ijoe.v16i01.12051 \\ Tom A. Eppes ${ }^{(凶)}$, Ivana Milanovic, Kamau Wright \\ University of Hartford, Connecticut, USA \\ eppes@hartford.edu
}

\begin{abstract}
During the past decade, the authors have sought to advance student research in a predominantly teaching institution. The two primary challenges were: academic - how to introduce and promote inquiry-based learning (IBL) given the constraints, and business - how to obtain and sustain funding in the area of industry-sponsored research. The authors developed a successful multidisciplinary modeling course that integrates four teaching and learning strategies and where key learning outcomes strengthen student readiness to engage in research. The course culminates with research performed as part of an IBL strategy that is relevant and supported by mentoring. The benefits include development of intellectual and practical skills that underlie a central activity of engineering design. The course structure, evidence of student work, and evolution over time to meet challenges are presented and discussed. Most importantly, the potential of this strategy to be implemented across other topical areas is addressed. Student participation in research improves learning of engineering and scientific concepts, increases interaction with faculty and industry sponsors, and provides opportunities for work in emerging technology areas. Benefits accrue both to students who pursue a research career and to those who enter applied fields by strengthening their ability to propose innovative solutions.
\end{abstract}

Keywords - Student research, inquiry-based learning, multidisciplinary modeling

\section{Introduction}

The authors' university is a private liberal arts institution with 600 undergraduate students enrolled in six accredited engineering programs, and about 100 students in the Master of Engineering. Among all programs, there is a balance between providing knowledge of human cultures and the world, and preparing students for the technical demands of the profession. A curricular review reveals mostly project-based technical courses with few credit hours possible outside the accreditation criteria requirements thus limiting research-related activities. Cornerstone, sophomore, and senior capstone design courses are in place $[1,2]$. Capstone projects have evolved from faculty- to 
industry-sourced topics where companies provide real-world problems, mentoring and financial support [3].

In addition, the University has long encouraged student research and actively promoted it within the Honors program, an annual undergraduate and graduate Research \& Creativity Colloquia and Symposia showcasing outstanding projects, as well as dedicated funding for targeted underrepresented students such as the Women's Advancement Initiative. Consequently, student resumes feature not only grade-point averages and graduate record examination scores, but are rich with examples of creative work, participation in University colloquia and symposia, and professional conferences including paper presentations. A subset of students, stimulated by increasingly competitive searches for internships and a desire to pursue prestigious jobs and graduate fellowships, seeks additional opportunities to broaden their knowledge base. These types of extracurricular research activities may be funded by modest competitive stipends such as College Faculty-Student Research or NASA Connecticut Space Grant Consortium (CTSGC) grants.

Given the numerous project-based undergraduate courses, and the course-only Master of Engineering with a significant project-component, there was a clear need for a broader strategy inclusive of inquiry-based learning (IBL). This paper builds on two prior conference publications and describes our efforts to strengthen student readiness to perform research by designing a multidisciplinary course with an IBL component [4, 5]. The course elements and structure have the potential to be implemented across a wide range of topical areas within the engineering curricula.

\section{Educational Context}

The term undergraduate research implies some original work as a final product by [6] while a broader definition is inclusive of the overall student experience and development in [7]. Considerable differences in perceiving the nature of undergraduate research and its ties with the curriculum stem from developments in the United States higher education over the last fifty years. When MIT launched its Undergraduate Research Opportunities Program (UROP) in 1969, the concept of undergraduates working on faculty-mentored effort was novel [8]. Students could choose either a faculty project or recruit another faculty interested in their idea and receive academic credit for the work carried out. Research teams could apply for outof-pocket expenses and seed funding, and the UROP stipends were made available during the summer to promote continuing participation [9]. The Council on Undergraduate Research (CUR), founded in 1978, defines undergraduate research as an inquiry or investigation that makes an original intellectual or creative contribution to the discipline. However, as noted by Jenkins and Healey [7], CUR promotes learning through research irrespective of the knowledge type and in parallel emphasizes original contribution.

Education by means of discovery that was possible in society with a relatively simple knowledge base began to face challenges in the second half of $20^{\text {th }}$ century [10]. A shift from elite to universal higher education and knowledge growth have 
significantly increased the cost of higher education while federal, state, and corporate support has not adequately responded to this worsening condition. The 1986 Neal Report documented a number of quality problems in undergraduate infrastructure, a funding focus on graduate education and research, and a low-level of support for initiatives by the National Science Foundation (NSF) [11]. In response, the NSF started funding research experiences for undergraduates and created recognition awards for the integration of research and education. While the 1998 Boyer Report advocated changes in undergraduate education at research-oriented universities, its recommendations to strengthen the research experience have resonated across the higher education landscape [12]. A research-based learning standard, an inquiry-based first year curricula, and a culminating capstone experience collectively required a shift in the educational paradigm from teaching to learning and discovery.

Over the last decade, educational proponents have advocated far-reaching efforts to increase the quality of undergraduate education. In 2005, the Association of American Colleges and Universities (AACU) launched the initiative, Liberal Education and America's Promise (LEAP): Excellence for Everyone as a Nation Goes to College. LEAP recommends that students acquire four blocks of essential learning abilities, one of which consists of intellectual and practical skills [13]. Inquiry and analysis, critical and creative thinking are two skills essential to engineering design, a central activity within the discipline. One built on LEAP by arguing that adoption of the Student as Scholar Model both draws on and adds to the impact of liberal education on student learning [14]. This influential work provided an integrating framework for highly effective long-term learning.

\section{A Tale of Three Models}

Three pedagogical models are found in engineering education: problem-, project-, and inquiry-based learning. Readers may find terms somewhat confusing for two reasons: the education landscape is saturated with many different types of '-based learning,' and the same terms are used in K-12 education, medical, business, law, engineering and other diverse curricula. Consequently, many research and review papers have been published on the aforementioned approaches to learning [15-17]. Below, two definitions are adapted from Dym [15]:

- Problem-based learning (PBL) deals with know-why, the solution of theoretical problems through the use of any relevant knowledge, whatever discipline the knowledge derives from

- Project-based learning (PBL) deals with know-how, the practical problems of constructing and designing on the basis of a synthesis of knowledge from many disciplines

- Inquiry-based learning (IBL) is a student-centered, active learning approach focused on questioning, and critical thinking [17]

Justice envisioned IBL as a loop of learning, shown in Fig.1, that facilitates change and growth as the original inquiry leads to new interests and more questions [18]. The 
entry points are active responsibility for learning and an understanding of the collaborative possibilities of knowledge production. The investigation of solutions creates new knowledge through information gathering, processing, and reflecting [16]. Self-reflection and evaluation are both products and drivers of success at every stage. IBL has been shown to be both an effective form of pedagogy $[19,20]$ and an important means of connecting research with teaching [21].

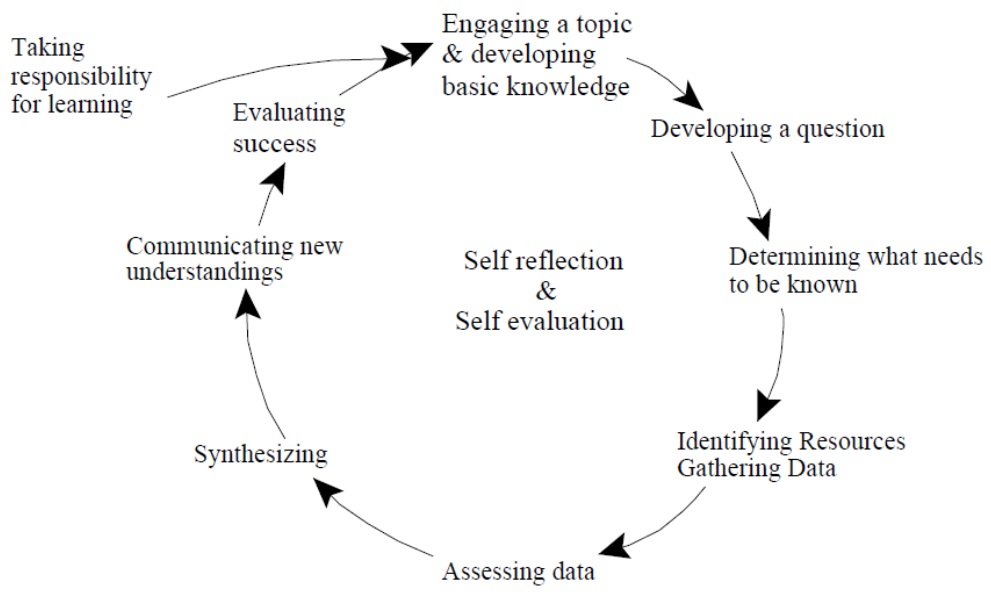

Fig. 1. The Inquiry Process [19]

After recognizing the need to embed an IBL approach within the engineering curricula, development of a course with a research component was undertaken. A broader goal was to ensure that its elements could be implemented across other topical areas. The next section describes how student learning is supported using scaffolded assignments that culminate in a research product. The observed benefits to date include improved intellectual and practical skills that focus on the central activity of engineering design.

\section{$4 \quad$ Background}

Our focus on multiphysics research began in 2005 with externally funded work on advanced laser processing as applied to the aerospace manufacturing industry. One project focused on percussion laser drilling of jet engine components with the objective of creating an integrated model of the fabrication process including the thermal, fluid, optical, electromagnetic, chemical, and kinetic effects. A facultystudent team developed a standalone computer application that simplified the steps required to identify the settings needed to produce a desired hole size and shape. The first release was requested by and distributed to over 30 industry entities. Encouraged by the positive user feedback and reception at conferences, a second release included a process optimization enhancement. 
At this point, the idea of improving student readiness to perform research was combined with the development of a course focused on the methods and techniques of multiphysics modeling with an IBL component. The choice of COMSOL software for use in the classroom has been validated by a number of pedagogical studies. COMSOL-based simulations have been used to improve teaching effectiveness in thermodynamics [22], fluid mechanics [23], and electrical engineering photonics courses [24], as well as senior chemical engineering laboratory [25]. The common threads reported are improved teaching effectiveness and enhancement of student learning along with other benefits such as easy visualization of difficult theoretical concepts, introduction to simulation methodology, and increased satisfaction with the overall experience.

\section{$5 \quad$ Multidisciplinary Modeling Course}

The multidisciplinary modeling course, initiated in 2011, consists of three credits and transpires over a 15 week semester. It is open to engineering graduate and undergraduate students with senior standing. All students, upon entering the course, will have covered similar mathematical, mechanical, and electrical topics. Knowledge of numerical methods is not required; however, many students have taken such a course as part of a minor in mathematics. For most of our students, this is the first encounter with numerical simulations since only mechanical engineering majors take a third year computer-aided design and analysis course.

The teaching and learning strategies were developed by the authors who have advanced degrees in the disciplines of electrical, mechanical, and computer engineering. The course is currently taught by one instructor at a time although other approaches are being explored. The course design strategies are:

- Cooperative learning in teams

- Scaffolding within a series of assignments building competency

- Contextualized weekly projects with a focus on relevant topics

- Inquiry-based learning

The simulation assignments are organized into three modules:

- Classical with prescribed outcomes

- Higher level transitional

- An IBL initiative

This structure builds on existing skills and knowledge, connects them in a logical way, and engages students in inquiry and learning.

Module 1 (Classical) familiarizes students with the simulation process and the software interface using step-by-step instructions on how to create a model, visualize results, and write formal reports. The learning outcomes are basic proficiency in modeling and simulation, post-processing or outcomes, and technical documentation. The classical projects involve everyday examples of simple devices that combine mechanical and electrical aspects such as: temperature distribution in an electrical 
heat sink, heating in an electrical busbar, and gas flow inside an incandescent light bulb. The first project (heat sink) introduces a flexible geometry using variables and parameters that can be easily changed. In the second project (busbar), large currents between two electrical supply lines cause temperatures to rise due to localized heating while the final assignment examines the flow of argon gas inside an incandescent light bulb. Two- and three-dimensional snapshots of the gas velocity flow field are shown in Fig. 2. As the argon heats up, students are able to visualize changes in gas temperature and create a movie depicting the motion of gas molecules over time.

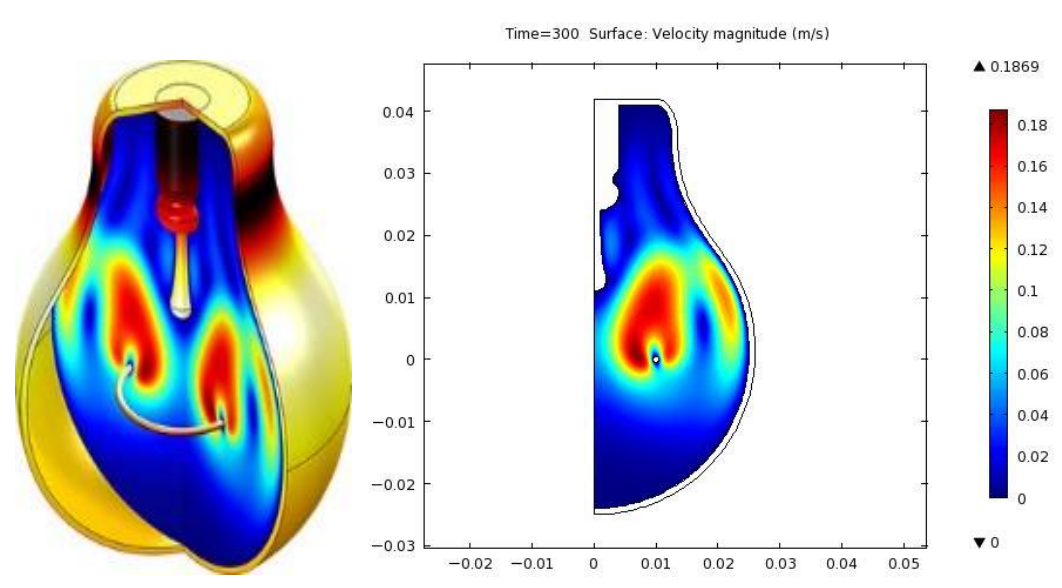

Fig. 2. Module 1 (Classical): Light Bulb

Module 2 (Transitional) has defined objectives; however, some design elements are intentionally left out prompting students to discover what is missing so that meaningful results can be acquired. Students are also asked to provide a unique element to their project, such as a change to the design or add a new post-processing component.

This requirement helps the learner develop a question on the topic they are already familiar with, determine what else could be explored in the process, and finally communicate new results and understandings without following a template. The learning outcomes are: better understanding of modeling complexities, greater involvement in collection and synthesis of relevant information, and ultimately enhanced technical skills.

The transitional projects are: an immersed oil bubble that rises from a submerged initial position under water (Fig. 3), the radar cross-section created by a nautical vessel, and heat conduction within a copper-layered slab of silica glass. 


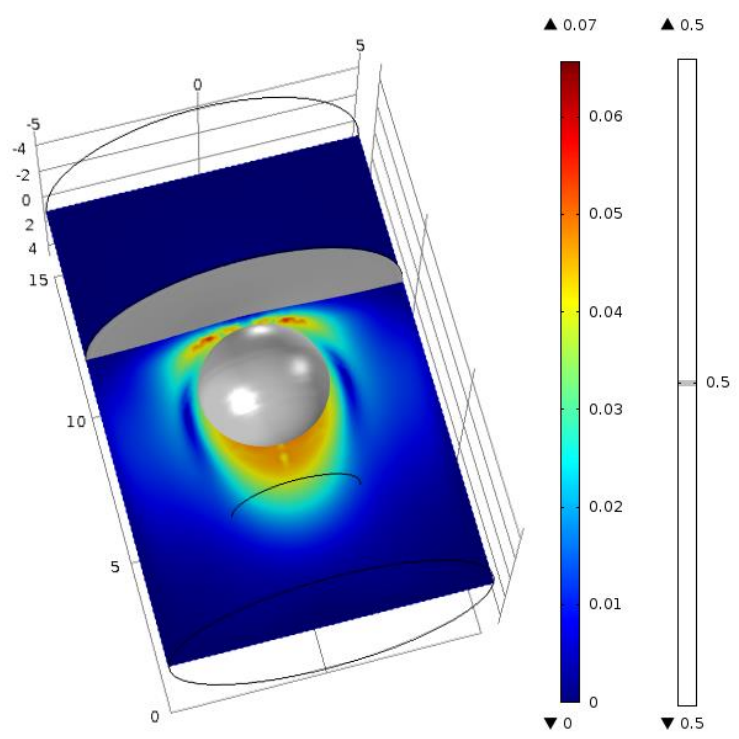

Fig. 3. Module 2 (Transitional): Oil Bubble in Water

The above scaffolded classical and transitional projects provide the necessary foundation for Module 3 (IBL Initiative) which is the culminating experience in which students are required to integrate prior skills into an independent research effort. Students propose, plan and execute a design that is of their interest, relevant to the course topics, and suitable in rigor. Work begins with teams generating concepts and filtering them down to a single proposal. They then research relevant information and evaluate alternatives within the construct of the model. At this point, students synthesize a design and generate a solution while working within the resource limitations and time constraints. At an end-of-the-semester event, each team delivers a formal oral presentation and submits a technical report.

Figures 4 and 5 provide an example of student research in the areas of biomimetic flight and optical fiber drawing, respectively. Module 3 is the most challenging, due to students' pre-conceived notion that it is just another project, the open-ended nature of research, and the limited amount of time (approximately half of the semester). Consequently, in parallel with skillset and technical knowledge building, strategies and resources are introduced that are necessary to engage students in a research topic of their interest from the beginning of the semester. Although our approach to IBL was developed by trial and error, we later found that it closely resembles the inquiry process described by Justice [19]. 


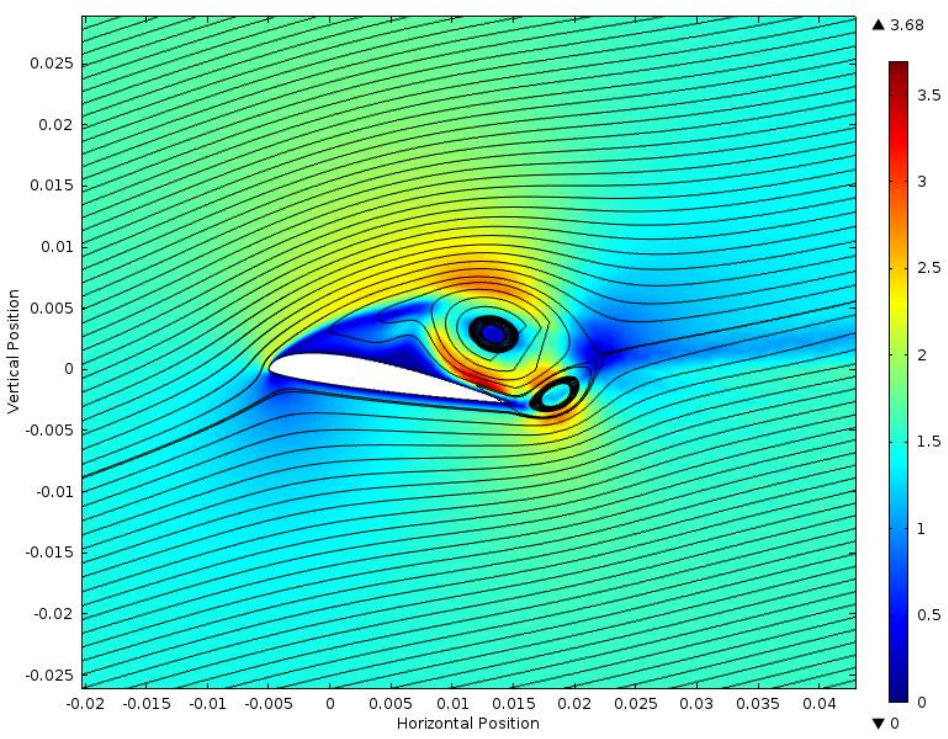

Fig. 4. Module 3 (IBL: Biomimetic Flight, Student A, Velocity Field in Plunge Cycle)

Ample information on the ultimate objective of the course is provided at the beginning of the semester. This course element cannot be underestimated since the prevalence of built-in project-based courses inherently results in over-reliance on the faculty to provide a menu of choices, identify resources, and supply relevant literature background. Moreover, the challenge here is to facilitate building of modeling skills through scaffolded projects and, in-parallel, help engage students in a topic of their interest. The benefits of the approach are:

- Students self-monitor, reflect and assume greater responsibility

- Instructors move from overseers to mentors

- Liberal education and modeling skills are strengthened and integrated

- Knowledge across topical areas is synthesized

- The quality of student work is improved

One course requirement involves developing a research question and ultimately a research proposal due at mid-semester. The research question and proposal elements are discussed on a weekly basis from the outset to prepare students for this part of the course. After five offerings, we concluded that a list of qualities of a good inquiry question was necessary to guide students in their reflection on the potential topic. Table 1 illustrates the quality components and descriptors adapted from Justice et al. (2007) for use in the IBL portion of the course. 
Table 1. Qualities of a good inquiry Question adapted from Justice [21]

\begin{tabular}{|l|l|}
\hline \multicolumn{2}{|c|}{ Inquiry Question } \\
\hline Quality & Contextual Descriptor \\
\hline Interesting & Both relevant to the course theme and personally interesting \\
\hline Analytical & Leads to answers that require consideration of multiple physics \\
\hline Problematic & Based on a technical issue \\
\hline Complex & Has more than one realistic possible answer \\
\hline Important & $\begin{array}{l}\text { Either argued in engineering community or its answer would have some real effect } \\
\text { on the world }\end{array}$ \\
\hline Genuine & $\begin{array}{l}\text { Something that the asker really wants to answer but presently cannot, as opposed } \\
\text { to a question which the asker assumes the answer and wants to prove }\end{array}$ \\
\hline Researchable & There is evidence that pertains to it \\
\hline
\end{tabular}

It is important that the learner has both interest in and intimate knowledge of the proposed topic. To facilitate deeper understanding of the material, students are required to write weekly about their research and share knowledge with peers and faculty. This process is helpful on multiple levels. A literature survey is not one-time event, repeated searches are necessary to cover the breadth of the topic to pose a reasonable research question. The use of academic papers and reputable web-based materials quickly accumulates into a significant and potentially overwhelming database. Editing and synthesizing information as well as communicating on weekly basis are critical for good understanding and scaling of the technical problem.

The course is without major exams so performance is assessed through weekly reports and the IBL deliverables that include a technical report and oral presentation. Each weekly project is assessed based on an online quiz that counts for $20 \%$ and a technical report that counts for the remaining $80 \%$. A total of seven projects are included in the first two modules of the course.

During the IBL module, informal status meetings are held with the faculty throughout the second part of the semester help prepare for a final presentation of about 20 minutes. Students provide a short summary (up to 300 words) of their work to the audience on the day of the oral presentation. The IBL technical report is written according to the best engineering practices and with the use of faculty developed checklist to facilitate learners' reflection on what has been done, both how and why.

Multidisciplinary experience is gained in each module in a number of ways. Students encounter problems:

- Outside of their major

- Within the major but with multiple coupled physics

- Across disciplines

Modules 1 and 2 are carefully chosen to span an array of physics, physical dimensions, and study types. For example, mechanical majors are exposed to modeling of electromagnetics or photonics phenomena and electrical majors are faced with heat transfer and fluid flow problems. Finally, a student may choose to engage in a research that encompasses more than one set of physics equations or requires physics outside of the primary discipline. 


\section{Results to Date}

The multidisciplinary modeling course has been offered a total of eleven times to date with a cumulative completion of 324 out of 331 enrolled. During the course, work is performed in stages with skills and resources introduced in the timely manner. While simulation capabilities are relatively easily developed, engaging in a topic that is of particular interest and building the knowledge base has been a challenge. Students have sufficient information on the requirements for Module 3 from the beginning of the semester as well as examples of previous studies, but only about $20 \%$ came up with an original research question and adequate background work in time for the proposal presentations. Many began the IBL initiative as simply another project with the expectation that the faculty provide a menu of projects, resources and literature. Despite these difficulties, most students successfully completed the course, and significant improvement was observed over the semester in their ability to document and present results. Table 2 illustrates the wide range of topics that have been explored by students.

Table 2. Recent IBL initiatives and associated physics

\begin{tabular}{|c|c|c|c|}
\hline Heat Transfer & Fluid Mechanics & AC/DC \& RF Fields & Solid Mechanics \\
\hline Disc Brake Heating & Biomimetic Flight & Patch Antenna Design & Airplane Landing Gear \\
\hline Heat Exchanger & impinging jet & Electro-optical Device & Guitar Resonance \\
\hline \multicolumn{2}{|l|}{ Microfluidic Mixer } & Power Transformer & Artificial Foot \\
\hline \multicolumn{2}{|l|}{ Optical Fiber Drawing } & Moving Coil Voltage & Impeller Vibration \\
\hline \multicolumn{2}{|c|}{ Electrical Heat Sink Design } & Inductive Power Transfer & Sound From a Gong \\
\hline \multicolumn{2}{|c|}{ Percussion Laser Drilling } & & Stress in a Bridge \\
\hline \multicolumn{2}{|l|}{ Multibody Dynamics } & Rotating Machinery & Semiconductors \\
\hline \multicolumn{2}{|l|}{ Sheet Metal Press } & Electrical Generator & Field-Effect Transistor \\
\hline \multicolumn{2}{|l|}{ Billiard Ball Collision } & Synchronous Motor & \\
\hline \multicolumn{2}{|c|}{ Internal Combustion Engine } & Brushless Motor & \\
\hline
\end{tabular}

After completing the course, twenty-one students have demonstrated success in obtaining research funding and/or creating formal work products. Specifically, 14 projects have obtained funding, 12 presentations were given at University showcases, 13 papers, one engineering report and two software releases were published.

To strengthen the financial incentive and promote greater relevance, the current emphasis is to increase the proportion of IBL initiatives that are industry-sponsored. The objective is to secure funding for student research at the G and UG levels for a scope of work lasting one to two semesters. One of our approaches is to request items that appear on a sponsor's internal 'to-do' list but get dropped due to budget priorities. By leveraging our existing relationships with companies in the area, particularly with representatives on college or department advisory boards, we have been successful obtaining stipends in the order of \$3-5KUSD per semester.

To illustrate student work, three IBL initiatives are now presented. Student A performed a simulation of biomimetic flight by investigating the air flow over a wing undergoing simultaneous pitch and plunge motion. Low velocities associated with 
aquatic, flying and gliding animals are of considerable interest to the aerospace community due to their importance in understanding the fundamental principles of flight in nature and the practical issues faced by micro-aerial vehicles (MAVs). Figure 4 is a snapshot of the air flow pattern during one plunge cycle in which two vortices are evident. Such structures are important because they can increase drag and negatively affect wing performance. This work resulted in a study of biomimetic flight, research proposal to CTSGC, Research and Creativity Colloquium presentation and, ultimately, contributed to a Regents' Honor Award for Undergraduate Students.

Student B had an interest in the area of turbomachinery such as those used in jet engines. However, the research topic originally proposed was too time consuming so the faculty mentor suggested a simpler geometry of a gas jet impinging on a wallmounted cube that had both experimental and simulation data available in an open literature. The investigation of complex vortical flow was a good match to the student's interest and capability, and the research product was presented at an annual COMSOL conference as well as published in the proceedings. Student B was presented with a Regent's Honor Award for Graduate Students.

The third IBL initiative was performed by student team $\mathrm{C}$ as an industry-funded investigation of the optical fiber drawing process. This research topic was sourced from a manufacturer of specialty optical fiber products. The requirement was to provide a simulation featuring a user-friendly interface that could be used to improve production speed and product consistency. Optical glass fibers are typically fabricated from glass preforms in a vertical drawing process at temperatures near the softening point of the glass. A drawing tower is shown in Fig. 5A. A solid glass preform enters the draw furnace cooled with nitrogen (Fig. 5B), and a thin fiber is pulled continuously from the neck-down region where melting and re-solidification occur (Fig. 5C). Optical fiber manufacturing is a multi-billion dollar industry hence even small improvements in processing speed can yield large savings. Most companies require nondisclosure agreements with the University thus we cannot disseminate the findings that were documented in a report.
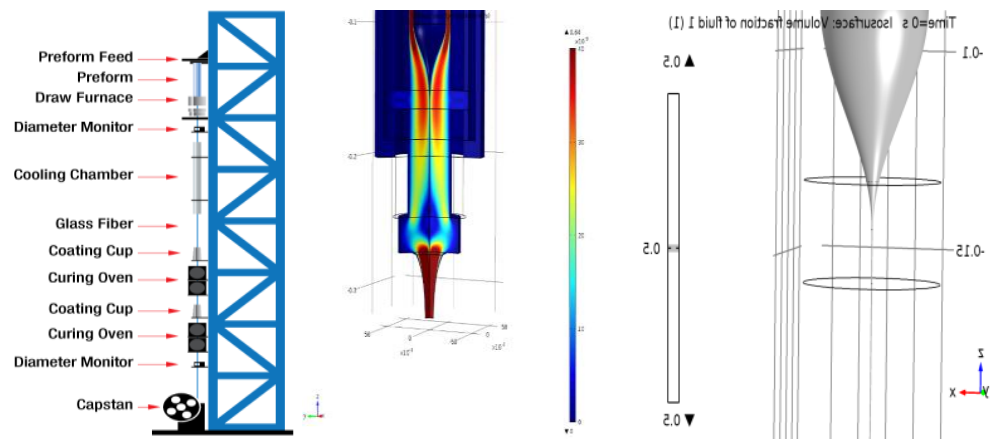

Fig. 5. Module 3 (IBL Initiative): Optical Fiber Drawing Process, Student Team C

(a) Fiber drawing facility [26], (b) Nitrogen gas velocity, and (c) Melting silica glass 


\section{Conclusion}

Our approach to increasing the scope and quality of our graduate and undergraduate research has been successful. The course has a $98 \%$ completion rate and contains an IBL component that better equips students with the ability to engage in relevant and advanced topics. After the course, 5\% of the students have demonstrated one or more of the following accomplishments: securing funding or creating formal work products consisting of published papers, presentations at a University showcases, and/or software releases.

Three examples, each representing a challenging modeling and simulation effort, were presented to show specific results that have been achieved. Continued interest among students in the simulation course and subsequently in pursuing mentored research promises even more interesting results in the future. Our current strategy is to introduce modeling and simulations earlier in the undergraduate curriculum so students who enter the multidisciplinary course will already possess a baseline of skills with the software. Having a larger and better equipped pipeline of students will enable us to grow the proportion of externally-funded work by leveraging a broader cross section of industry contacts.

\section{$8 \quad$ References}

[1] Shetty, D., Alnajjar, H., Leone, D., Keshawarz, M. S., Nagurney, L., \& Smith, L. (2001, June), Integrating Engineering Design With Humanities, Sciences And Social Sciences Using Integrative Learning Blocks. Paper presented at 2001 Annual Conference, Albuquerque, NM. https://peer.asee.org/9414.

[2] Shetty, D., \& Sahay, C. (2003). Innovative Integrated Mechanical Engineering Curriculum, ASME Curriculum Innovation Award Honorable Mention.

[3] Eppes, T. A., \& Milanovic, I. (2011). Capstone Design Project Course Pathways. Am. J. Eng. Educ., 2(1), 35-42.

[4] Milanovic, I., and Eppes, T. A., (2015). Improving Student Readiness for Inquiry-Based Learning, Proceedings of ASME-JSME-KSME Joint Fluids Engineering Conference. Paper AJK2015-01648. Seoul, Korea. https://doi.org/10.1115/ajkfluids2015-1648

[5] Eppes, T. A., and Milanovic, I., (2015). Forging a Sustainable Student Research Initiative. ASEE Proceedings of ASEE Annual Conference. Paper ASEE-2015-11176. Seattle, WA. https://doi.org/10.18260/p.24125

[6] Kinkead, J. (2003). Learning Through Inquiry: An Overview of Undergraduate Research. New Dir. Teach. Learn, 2003(93), 5-18. doi: 10.1002/tl.85

[7] Healey, M., \& Jenkins, A. (2009). Developing Undergraduate Research and Inquiry. Research Report to the Higher Education Academy. https://www.heacademy.ac.uk/node/ 3146 [last accessed Jun 23 2016].

[8] McCluskey, E. (2009). Undergraduate Research Opportunities Program marks 40th year. Available from: http://www.technologyreview.com/article/414003/the-soul-of-mit/ [last accessed Jun 23 2016].

[9] Cohen, S.A., \& McVicar, M.L.A. (1976). Establishing an undergraduate research programme in physics: how it was done. Am. J. Phys. 44(3), 199-203. Council on Undergraduate Research (CUR) (n.d.) Definition of undergraduate research. http://www. 
cur.org/about_cur/fact_sheet/ [last accessed Jun 23 2016]. https://doi.org/10.18833/curq/3 $\underline{7 / 2 / 14}$

[10] Clark, B. R. (1997). The modern integration of research activities with teaching and learning. J. High. Educ., 68(3), 242-255.

[11] National Science Board, Task Committee on Undergraduate Science and Engineering Education, H. A. Neal (chair). Undergraduate Science, Mathematics and Engineering Education; Role for the National Science Foundation and Recommendations for Action by Other Sectors to Strengthen Collegiate Education and Pursue Excellence in the Next Generation of US Leadership in Science and Technology. National Science Foundation publication no. NSB 86-100. Washington, DC: National Science Foundation, 1986. https:// doi.org/10.2172/548856

[12] Boyer Commission on Educating Undergraduates in the Research University, S. S. Kenny (chair). Reinventing Undergraduate Education: A Blueprint for America's Research Universities. State University of New York-Stony Brook, 1998.

[13] Association of American Colleges and Universities. (2005). Liberal Education and America's Promise (LEAP): Excellence for Everyone as a Nation Goes to College. Wash., DC.

[14] Hodge, D., Pasquesi, K., \& Hirsh, M. (2007). From Convocation to Capstone: Developing the Student as Scholar, Keynote address, Association of American Colleges and Universities Network for Academic Renewal Conference, April 19-21, Long Beach, California. Available from:https://miamioh.edu/_files/documents/about-miami/president/ reports-speeches/From_Convocation_to_Capstone.pdf [last accessed Jun 23 2016].

[15] Dym, C. L., Agogino, A. M., Eris, O., Frey, D. D., \& Leifer, L. J. (2005). Engineering design thinking, teaching, and learning. J. Eng. Educ., 94(1), 103-120. https://doi.org/10.10 02/j.2168-9830.2005.tb00832.x

[16] Savery, J. R. (2006). Overview of Problem-based Learning: Definitions and Distinctions. Interdisciplinary J Problem-Based Learning, 1(1). https://doi.org/10.7771/1541-5015.1002

[17] Pedaste, M., Mäeots, M., Siiman, L. A., de Jong, T., van Riesen, S. A. N., Kamp, E. T., Manoli, C. C., Zacharia, Z. C., \& Tsourlidaki, E. (2015). Phases of inquiry-based learning: Definitions and the inquiry cycle, Educ. Res. Rev., 14, 47-61, ISSN 1747-938X, https:// doi.org/10.1016/j.edurev.2015.02.003.

[18] Justice, C., Warry, W., Cuney, C., Inglis, S., Miller, S., Rice, J., Sammon, S. (2001). A grammar for inquiry: Linking goals and methods in a collaboratively taught social sciences inquiry course. Society for Teaching and Learning in Higher Education, The Alan Blizzard award paper: The award winning papers. Windsor, Ontario, Canada: McGraw-Hill Ryerson.

[19] Justice, C., Rice, J., Roy, D., Hudspith, B., \& Jenkins, H. (2009). Inquiry-based learning in higher education: administrators' perspectives on integrating inquiry pedagogy into the curriculum. High. Educ., 58(6), 841-855. https://doi.org/10.1007/s10734-009-9228-7

[20] Justice, C., Rice, J., Warry, W., Inglis, S., Miller, S. \& Sammon S. (2007). Inquiry in higher education: reflections and directions on course design and teaching methods. Innovat. High. Educ., 31(4), 201-14. https://doi.org/10.1007/s10755-006-9021-9

[21] Healey, M. (2005). Linking research and teaching exploring disciplinary spaces and the role of inquiry-based learning, in Barnett, R. (ed). Reshaping the university: new relationships between research, scholarship and teaching, 30-42. Maidenhead: McGrawHill/Open University Press. https://doi.org/10.1108/09684880710830008

[22] Ngabonziza, Y., \& Delcham, H. (2014). The Enhancement of Students Learning Through COMSOL Simulation Projects. Proceedings of 2014 ASEE Zone 1 Conference, Bridgeport, CT, pp. 1-6. https://doi.org/10.1109/aseezone1.2014.6820674 
[23] Kwon, H. J. (2012). Use of COMSOL Simulation for Undergraduate Fluid Dynamics Course. Proceedings of 2012 ASEE Annual Conference, San Antonio, Texas. Paper AC 2012-4407. https://peer.asee.org/22167

[24] Yang, B., Huang, Y., Adams, R., Zhang, J., \& Burbank, K. (2008). Effective Teaching of Photonics E\&M Theory using COMSOL. Proceedings of 2008 ASEE Annual Conference, Pittsburgh, Pennsylvania. Paper AC 2008-1093. https://peer.asee.org/3670

[25] Clark, W, \& DiBiasio, D. (2007). Computer Simulation of Laboratory Experiments for Enhanced Learning. Proceedings of 2007 ASEE Annual Conference, Honolulu, Hawaia. Paper AC 2007-823. https://peer.asee.org/1937

[26] ThorLabs, Specialty Optical Fiber Manufacturing, http://www.thorlabs.com/newgroup page9.cfm?objectgroup id=6832\#ad-image- 0 .

\section{Authors}

Tom A. Eppes is a professor of electrical \& computer engineering at the University of Hartford. His area of expertise is multiphysics modeling and photonics. Dr. Eppes is a contributing author for more than 75 journal articles, conference papers, technical reports, and software releases. He is a member of the Institute of Electrical \& Electronics Engineers (IEEE) and American Society for Engineering Education (ASEE).

Ivana Milanovic is a professor of mechanical engineering at the University of Hartford. Her area of expertise is thermo-fluids with research interests in vortical flows, computational fluid dynamics, multiphysics modeling, and collaborative learning strategies. Dr. Milanovic is a contributing author for more than 80 journal articles, NASA reports, conference papers, and software releases.

Kamau Wright is an assistant professor of mechanical engineering at the University of Hartford. He specializes in thermo-fluids and plasma engineering. His technical research interests include applications of high voltage plasma discharges to liquids and wastewaters; fouling prevention and mitigation for heat exchangers; oxidation of organic matter in water; and inactivation of bacteria using high voltage plasmas.

Article submitted 2019-10-27. Resubmitted 2019-12-03. Final acceptance 2019-12-03. Final version published as submitted by the authors. 